\title{
UMBILICAL DIPHTHERIA
}

BY

\author{
A. GORDON SIGNY, L.R.C.P., M.R.C.S., \\ Assistant Pathologist and Research Fellow, \\ AND
}

R. DOUGI.AS BRUCE, M.B., Ch.B., House Surgeon.

(From the Hospital for Sick Children, Great Ormond Street, London.)

This unusual condition was first described in 1878 by Löwenstamm ${ }^{1}$ but the first authentic case proven by culture and post-mortem examination occurred in $1896^{2}$. The only English case was reported by Pitts $^{3}$ in 1897, also from this hospital, and in this the umbilical condition closely resembled that here recorded. In spite of laryngeal symptoms during life, Pitts found no changes in the larynx.

The largest number of cases occurred in an epidemic in Christiana in 1919 when there were 32 examples of umbilical diphtheria. Comby ${ }^{4}$ reviewing these cases divides them into three groups in order of severity:-(1) No clinical evidence of diphtheria; only proven on culture. (2) Limited ulceration around umbilicus covered with caseous deposit. (3) Widespread inflammation with œedema, necrosis and false membrane formation. Montgomery $^{5}$ reports a case with detailed post-mortem findings and a full bibliography.

\section{Case report.}

The clinical and pathological records of the present case of umbilical diphtheria are as follows:-

D. V., male, was admitted to hospital at 17 days old suffering from a sceptic umbilicus provisionally diagnosed as erysipelas.

The child's birth had been normal in every respect. The nurse had tied the cord, which had dropped off on the fourth day. On the 14th day the abdominal wall around the umbilicus was said to be red and raw. The nurse called and reported that she thought an abscess was going to form, and although the red area was small it looked as though it might spread. Three days latter (17th day) the child was admitted to hospital.

The patient was the youngest of eight children. Four of these had been removed to a fever hospital with faucial diphtheria during the six weeks preceding the patient's birth. Diphtheria was rampant in the district at the time. The last of of the children to be sent away was removed on the day of this patient's birth. 
On admission the child did not appear to be ill. It was well nourished and the temperature and pulse rate normal. A purulent exudate was oozing from the umbilicus which lay at the base of a crater one-tenth to one-eighth of an inch in depth, filled with a yellowish green slough, streaked with dark brown blood. Stretching for half an inch around was a punctate greyish white area dotted with small red spots, and beyond this was a further ring of brawny red skin.

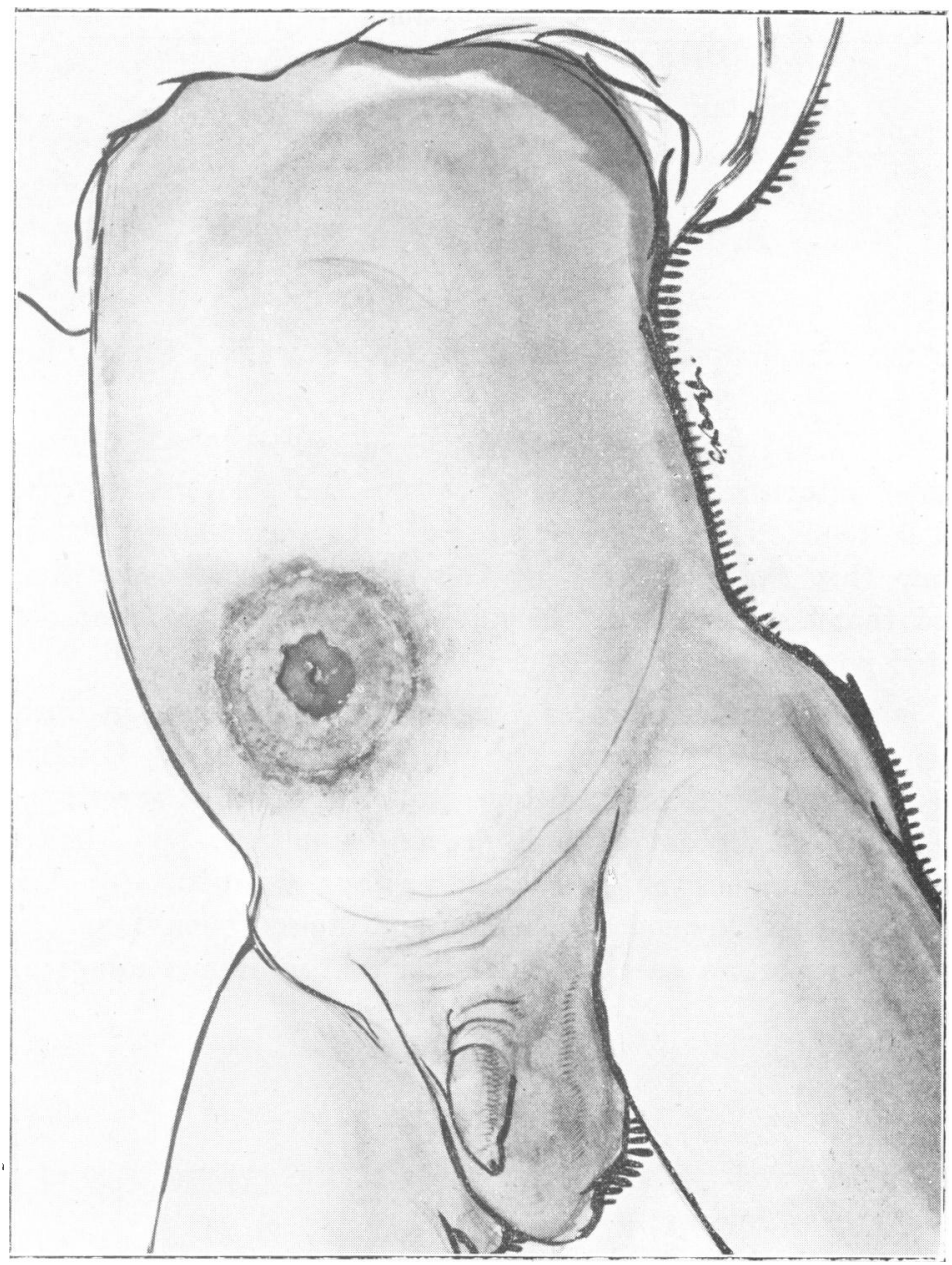

Fli. 1. From a photograph of a painting. The central crater ${ }_{10}^{1}$ th to ${ }_{4}^{1}$ th-in. in depth, showed a yellowish green slough. Round the crater was a yellow area showing many discreet red spots. The edge of the lesion was bright red, fading off into flushed skin.

Course. On the day after admission the temperature rose to $100 \cdot 6^{\circ} \mathrm{F}$. but then settled gradually to normal. For four days the peri-umbilical inflammation spread over the abdomen in spite of vigorous local treatment and then began to recede. The umbilicus and crater remained filled with slough.

Swabs were taken from the umbilicus with a view to identifying the infecting organism and throat swabs were also taken in view of the diphtheria history in the 
family. The throat and nasal swabs were negative, but from the umbilicus KlebsLoeffler bacilli were grown, in pure culture. They conformed to the normal carbohydrate fermentation tests and were very virulent to a guinea-pig. The patient was transferred to the North Western Fever Hospital where he died suddenly two days after admission, the 12th day of the illness.

Post-mortem examination (performed by Dr. Mair). The child was well nourished and of normal size. There was a large ulcer at the umbilicus, $1 \frac{1}{2}$ by 2 inches in extent, with necrosis and surrounding inflammation.

Macroscopically all the organs were quite normal. The fauces and nares were quite clean, and swabs taken from them post mortem showed no diphtheria bacilli. The umbilical swabs were again positive. The ulcer had a very indurated base, the induration extending right down to the peritoneum. The peritoneal cavity showed a little free fluid. The umbilical vein was normal. The heart muscle was slightly pale. The adrenals shewed some hæmorrhages.

Microscopically there was no abnormality of the heart muscle, but the adrenals showed intense congestion of the medulla.

\section{Discussion.}

Diphtheria occurring apart from the nasopharynx is a very unusual occurrence and is frequently fatal owing to the false membrane not being recognized as diphtheritic in origin. Umbilical diphtheria occurs in the newborn and in infants up to three weeks of age. Comby ${ }^{4}$ believes that at certain times diphtheria shows a tendency to attack unusual parts of the body, as in the Christiana outbreak of 1919. Of the other 30 authentic recorded cases many of the earlier ones were fatal, but those occurring in more recent times have been treated with anti-toxin and have recovered. In the present case diphtheria was not considered in the original diagnosis, the appearance being that of a severe cellulitis with sloughing. Actually it falls into the second group recorded above. The main features to be used as a guide in the diagnosis of umbilical diphtheria would appear to be:-

(a) The well nourished appearance of the child who is sucking wel! and is putting on weight normally.

(b) An inflamed umbilicus with false membrane formation.

(c) A normal temperature almost throughout the disease, quite out of proportion to the severity of the umbilical lesion which, if it were coccal, should be associated with fever; and

(d) Confirmation by bacteriological examination which should be sought in every infection of the umbilicus, particularly in children during the first month of life.

The treatment of these cases is the early administration of serum intramuscularly, to combat the toxæmia and prevent the onset of cardiac or neurological complications. In the case reported the diphtheritic nature was not recognized early enough to save the patient's life. 


\section{Summary.}

A case of umbilical diphtheria, confirmed by bacteriological examination, is recorded and the points of differential diagnosis are discussed.

We should like to thank Mr. Eric Lloyd under whose care the patient was, for permission to publish the case, and Mr. Charles Keogh for his illustration.

\section{REFERENCES.}

1. Löwenstamm, Med. Chir. Centrabl., Vienna, 1878, XIII, 89.

2. Toch, S., Prag. med. Wchnschr., Prague, 1896, XXI, 409.

3. Pitts, B., Lancet, London, 1897, i, 953.

4. Comby, J., Arch. de méd. d. enf., Paris, 1921,.XXIV, 437.

5. Montgomery, J. C., Am. J. Dis. Child., Chicago, 1930, XL, 968. 